\title{
Effect of Mn Modification on the Corrosion Susceptibility of Mg-Mn Alloys by Magnesium Scrap
}

\author{
Dong-Dong Gu ${ }^{1}$ Jian Peng ${ }^{1,2} \cdot$ Jia-Wen Wang ${ }^{1} \cdot$ Zheng-Tao Liu $^{1} \cdot$ Fu-Sheng Pan ${ }^{1,2}$
}

Received: 6 December 2019 / Revised: 23 January 2020 / Published online: 18 May 2020

(c) The Chinese Society for Metals (CSM) and Springer-Verlag GmbH Germany, part of Springer Nature 2020

\begin{abstract}
The microstructure and anti-corrosion behavior of $\mathrm{Mg}-\mathrm{Mn}$ alloys by magnesium scrap have been investigated in this study. The results show that the size of the Fe-rich particles in magnesium scrap decreases but the quantity increases with the Mn addition. Although the presence of Mn-containing Fe-rich particles with unique symbiotic structure can effectively weaken the micro-galvanic corrosion, the presence of more free $\mathrm{Fe}$ (Fe-rich particles) does not necessarily lead to severe corrosion of the alloy. The corrosion susceptibility of $\mathrm{Mg}-\mathrm{Mn}-\mathrm{Fe}$ alloy primarily depends on the solubility of iron in the $\mathrm{Mg}$ matrix, while it can be significantly reduced by suitable Mn addition. Besides, the tolerance limit of the Fe impurity can be expressed as $\mathrm{Fe}_{\max }=0.0083 \mathrm{Mn}$ (relative to the iron solubility). Only when the $\mathrm{Fe} / \mathrm{Mn}$ ratio is below 0.0083 can the alloy have excellent corrosion resistance, with the corrosion rate changing in the scope of $0.38 \pm 0.09$ to $0.54 \pm 0.15 \mathrm{mg} / \mathrm{cm}^{2}$ day and $i_{\text {corr }}$ from 3 to $9 \times 10^{-4} \mathrm{~A} / \mathrm{cm}^{2}$.
\end{abstract}

Keywords Magnesium scrap $\cdot$ Mn modification $\cdot \mathrm{Fe}$ impurity $\cdot$ Corrosion susceptibility $\cdot$ Corrosion resistance

\section{Introduction}

Magnesium and its alloys have the advantages of high specific strength, good machinability, excellent biocompatibility, etc., thus attracting more attention and enjoying a growing reputation when applied in many fields [1-4]. However, the extensive application of magnesium alloys was severely restricted by their relatively poor anti-corrosion ability.

It is well known that magnesium alloys are susceptible to galvanic corrosion caused by the second phase of impurities. Among the known impurities, the Fe element is the most common impurity and exists in almost every stage of the manufacturing process. Moreover, Fe impurity was proved to have significant toxic effect on the corrosion resistance of

Available online at http://link.springer.com/journal/40195.

Jian Peng

jpeng@cqu.edu.cn

1 State Key Laboratory of Mechanical Transmission, College of Materials Science and Engineering, Chongqing University, Chongqing 400044, China

2 Chongqing Research Center for Advanced Materials, Chongqing Academy of Science and Technology, Chongqing 401123, China the $\mathrm{Mg}$ alloys, causing increasing hydrogen evolution rate of the galvanic-type corrosion cell [5-8]. A lot of researches show that to keep the Fe impurity under an iron tolerance limit is a wise way to get excellent corrosion resistance and good mechanical properties [9-15]. As for pure $\mathrm{Mg}$, the iron tolerance limit was reported to be $170 \mathrm{ppm}[16,17]$. When the concentration of $\mathrm{Fe}$ impurities is lower than the tolerance limit, the adverse impact of Fe element on the corrosion resistance could be ignorable. But, it is very difficult to purify pure magnesium to a very high level in production practice.

Fortunately, the iron tolerance limit can be influenced by the third element and the casting process $[4,12,18$, 19]. Manganese element (Mn) can be found in the alloy brand standard of lots of commercial magnesium alloys (such as AZ series alloys, AM series alloys). One of the primary purposes of Mn addition is to combine Mn element with a certain amount of Fe element to form a higher density of $\mathrm{Fe}-\mathrm{Mn}$ compound, decreasing the iron concentration and then settling the Fe element into the melting sludge. Moreover, in the melted alloy liquid, the temperature determines the relative proportion of the dissolved iron and undissolved iron content [18]. In other words, as the melt temperature decreases, the dissolved iron content decreases, but the undissolved iron content increases. So, 
reasonable control of the $\mathrm{Mn}$ content and casting process helps improve the corrosion resistance of the alloy further. Generally, the $\mathrm{Mg}-\mathrm{Mn}$ alloy has good plasticity and corrosion resistance. However, with the increase in the proportion of magnesium scrap used in the $\mathrm{Mg}$ alloy production, it is important to study the corrosion resistance of $\mathrm{Mg}-\mathrm{Mn}$ alloys prepared from magnesium scrap with high iron content. Although extensive researches have been conducted, the investigation on suitable quantitative relationship between $\mathrm{Fe}$ and $\mathrm{Mn}$ concentrations and the corrosion sensitivity of magnesium alloys was still insufficient. It is well known that $\mathrm{Fe}$ impurity mainly exists as a solid-solution form and free form in the alloy [12]. However, the different roles of the two existing forms of $\mathrm{Fe}$ in the corrosion process were not fully understood. In the present work, a series of $\mathrm{Mg}-\mathrm{Mn}-\mathrm{Fe}$ alloys with varying proportions of magnesium scrap and $\mathrm{Mg}-\mathrm{Mn}$ master alloy were designed to get different $\mathrm{Fe} / \mathrm{Mn}$ ratios. The modification effects of $\mathrm{Mn}$ on microstructure and anti-corrosion behavior of the alloy made from magnesium scrap, as well as the roles of different existing forms of Fe element in the corrosion process, were investigated.

\section{Experimental}

\subsection{Material Preparation and Microstructure Characterization}

The magnesium scrap $(0.0423 \% \mathrm{Fe}$, mass fraction) and $\mathrm{Mg}-\mathrm{Mn}$ master alloy $(0.0123 \% \mathrm{Fe}$ and $3.25 \% \mathrm{Mn})$ were used as raw materials in this test. The $\mathrm{Mg}-\mathrm{Mn}-\mathrm{Fe}$ alloys were fabricated in a low carbon steel crucible under the protection of a shield gas consisting of $\mathrm{SF}_{6}$ and $\mathrm{CO}_{2}$ (1:100). After adding the $\mathrm{Mg}-\mathrm{Mn}$ master alloy into the crucible, the melt was kept at $750{ }^{\circ} \mathrm{C}$ for $30 \mathrm{~min}$ and then slowly cooled down to $650{ }^{\circ} \mathrm{C}$ and held for $90 \mathrm{~min}$ (with a temperature fluctuations of $\pm 15^{\circ} \mathrm{C}$, and cycle duration of 20 to $25 \mathrm{~min}$ ). After that, the crucible was quenched into cold water to obtain the solidified ingot. The chemical compositions of alloy samples cut from the half-height position of their ascast alloy ingots were determined by ICP-AES (Inductively Coupled Plasma-Atomic Emission Spectroscopy), as listed in Table 1. Specimens for microstructure characterization were ground with $\mathrm{SiC}$ emery papers and then dried in a cold air stream. The SEM (Tescan Vega 3 LMH and JEOL JSM-7800F field emission scanning electron microscope) equipped with energy-dispersive X-ray spectroscopy (EDS) was used to characterize the microstructure. The average size of the particles was evaluated by using Image-Pro Plus software, and the results were determined by averaging the values taken from at least five separate SEM images.
Table 1 Chemical composition of the Mg-Mn-Fe alloy samples (wt\%)

\begin{tabular}{lllll}
\hline Alloys & $\mathrm{Mn}$ & $\mathrm{Fe}$ & $\mathrm{Si}$ & $\mathrm{Mg}$ \\
\hline 1\# (Mg-0Mn-0.023Fe) & 0 & 0.0236 & 0.0179 & Bal \\
2\# (Mg-0.1Mn-0.023Fe) & 0.1090 & 0.0232 & 0.0188 & Bal \\
3\# (Mg-0.3Mn-0.020Fe) & 0.2780 & 0.0201 & 0.0203 & Bal \\
4\# (Mg-0.5Mn-0.018Fe) & 0.5030 & 0.0182 & 0.0171 & Bal \\
5\# (Mg-1.0Mn-0.018Fe) & 0.7610 & 0.0172 & 0.0206 & Bal \\
6\# (Mg-2.0Mn-0.010Fe) & 1.4890 & 0.0079 & 0.0200 & Bal \\
\hline
\end{tabular}

\subsection{Constant Immersion Testing and Corrosion Morphology Characterization}

The corrosion rate was evaluated by measuring the weight loss of alloy samples at room temperature in $3.5 \mathrm{wt} \% \mathrm{NaCl}$ solution for two days. The specimen's surface was mechanically ground to 1000 grit $\mathrm{SiC}$ paper, washed with distilled water and then dried in a stream of cold air. After the immersion test, the samples were washed with a chromic acid solution $\left(200 \mathrm{~g} / \mathrm{L} \mathrm{CrO}_{3}+10 \mathrm{~g} / \mathrm{L} \mathrm{AgNO}_{3}\right)$ at ambient temperature for about $15 \mathrm{~min}$ to remove the corrosion products and then quickly rinsed with distilled water and dried in the cold air. The measured metal weight loss (WL, $\mathrm{mg}$ ) was used to calculate the corrosion rate $(\mathrm{CR}, \mathrm{mg} /$ $\mathrm{cm}^{2}$ day) as follows:

$\mathrm{CR}=\frac{\mathrm{WL}}{A t}$,

where $t$ is the exposure period in days and $A$ is the total surface area in square centimeters. The corrosion morphology of the tested specimens was further characterized using scanning electron microscopy.

\subsection{Electrochemical Measurement}

The electrochemical test was conducted using a Metrohm Autolab PGSTAT 302 electrochemical workstation in a three-electrode cell composed of a reference electrode (a saturated calomel electrode), a counter electrode (a platinum foil) and a working electrode. The area of the working electrode was $0.785 \mathrm{~cm}^{2}$. EIS measurements were carried out at a certain corrosion potential in a frequency range from $100 \mathrm{kHz}$ to $0.01 \mathrm{~Hz}$ using a $10 \mathrm{mV}$ amplitude perturbation. Potentiodynamic polarization curves were plotted at a scanning rate of $1 \mathrm{mV} / \mathrm{s}$. The above reagents used were of GR grade or better. No stirring was applied to the solution during the experiments.

To get better understanding of the relationship between the iron content (including the dissolved and undissolved 
iron contents) and corrosion rate, the solid solubility of $\mathrm{Fe}$ in trial samples with different additions of Mn was got from $\mathrm{Mg}-\mathrm{Mn}-\mathrm{Fe}$ phase diagram. The content of free $\mathrm{Fe}$ is difference between the measured value (tested by ICP) and solid solubility of Fe.

\section{Results}

\subsection{Microstructure of Fe-Rich Particle}

The morphology and EDS results of the Fe-rich particles in $1 \#(0.0236 \% \mathrm{Fe}, 0 \mathrm{Mn})$ and $4 \#(0.0182 \% \mathrm{Fe}, 0.503 \% \mathrm{Mn})$ alloys after mechanical grinding are shown in Fig. 1. Fe impurities in the alloy mainly exist in the form of solid solutions and free forms (Fe-rich particle). As seen in Fig. 1a, c, e, 1\# alloy has several Fe-rich particles with an average size of $0.72 \mu \mathrm{m}$. Sharing similar structure as particles of sample $1 \#$ alloy, the Fe-rich particles in 2\# alloy have a brighter inner layer and slightly darker outer layer. However, the Fe-rich particle of $4 \#$ alloy has a more pronounced flocculating structure than that of the 1\# alloy. Moreover, with $\mathrm{Mn}$ addition, the size of Fe-rich particles decreases but the number increases, indicating that the Mn element inhibited the coarsening process of the Fe-rich particles in the melt, and its details will be reported in future research.
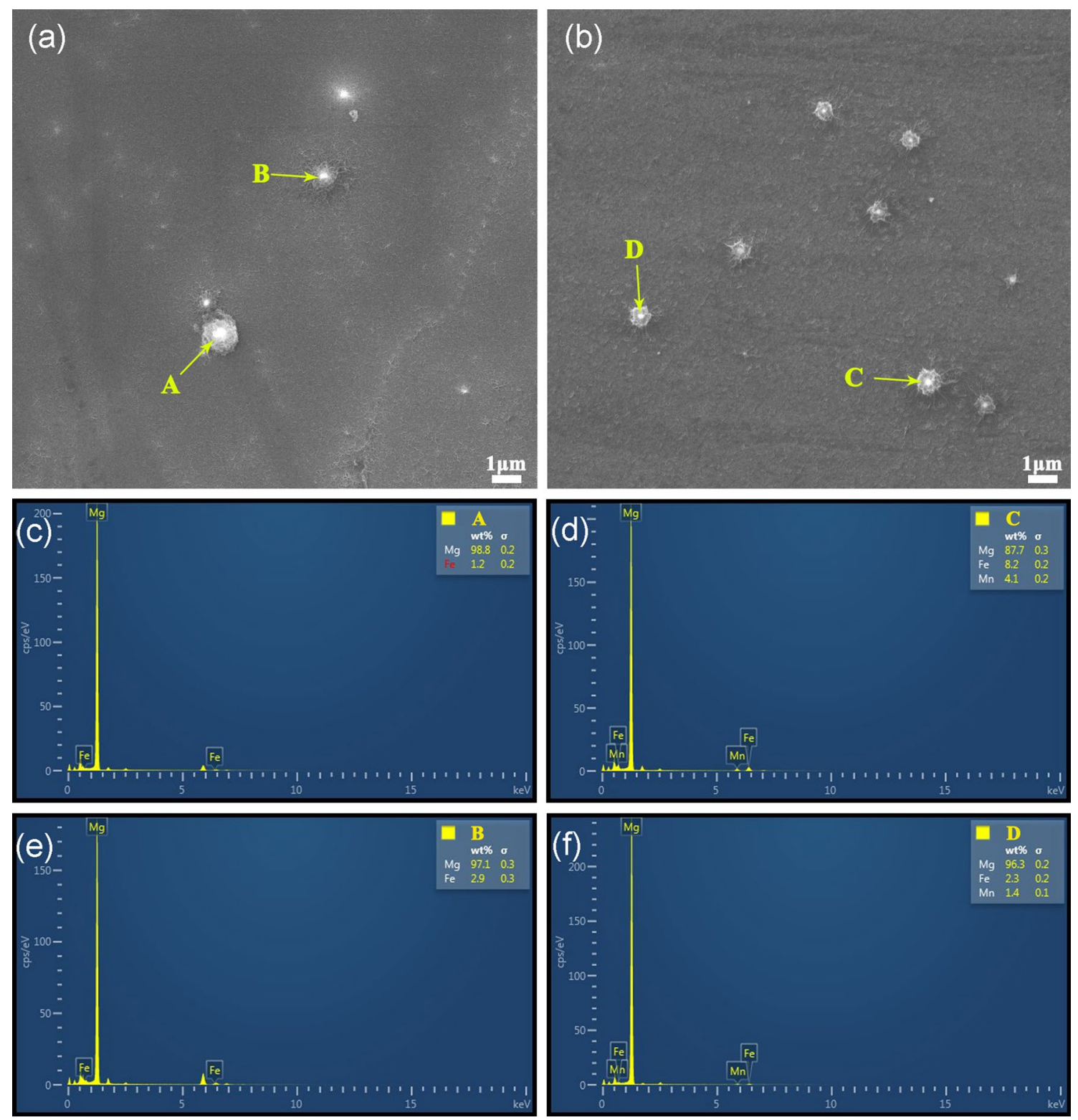

Fig. 1 SEM images and EDS results of Fe-rich particles: a, c, e 1\# alloy, b, d, f 4\# alloy 
To better analyze the trend of element intensity $(\mathrm{Fe}$, $\mathrm{Mn}$ and $\mathrm{Mg}$ ) around Fe-rich particles, EDS line scanning was employed, with its results being shown in Fig. 2. The intensity of $\mathrm{Fe}$ element of $\mathrm{Fe}$-rich particles in 1\# alloy reaches the maximum peak value at the core (see Fig. 2a) and then decreases gradually along the radial direction, while the intensity of $\mathrm{Fe}$ and $\mathrm{Mn}$ elements of the $\mathrm{Fe}$-rich particles in 4\# alloy reaches the peak value at the same site (the center of the brighter inner layer), both of which have the same changing trend along the radial direction of the particle (see Fig. 2b). Hence, the particles containing $\mathrm{Fe}$ and $\mathrm{Mn}$ should be a coupled growth microstructure (symbiotic structure), which is consistent with the previous hypothesis of Kim's [20]. The presence of Mn in Fe-rich particles may cause Mn and Fe to create a buffer zone and form the symbiotic structure, thus contributing to weakening the effect of micro-galvanic corrosion.
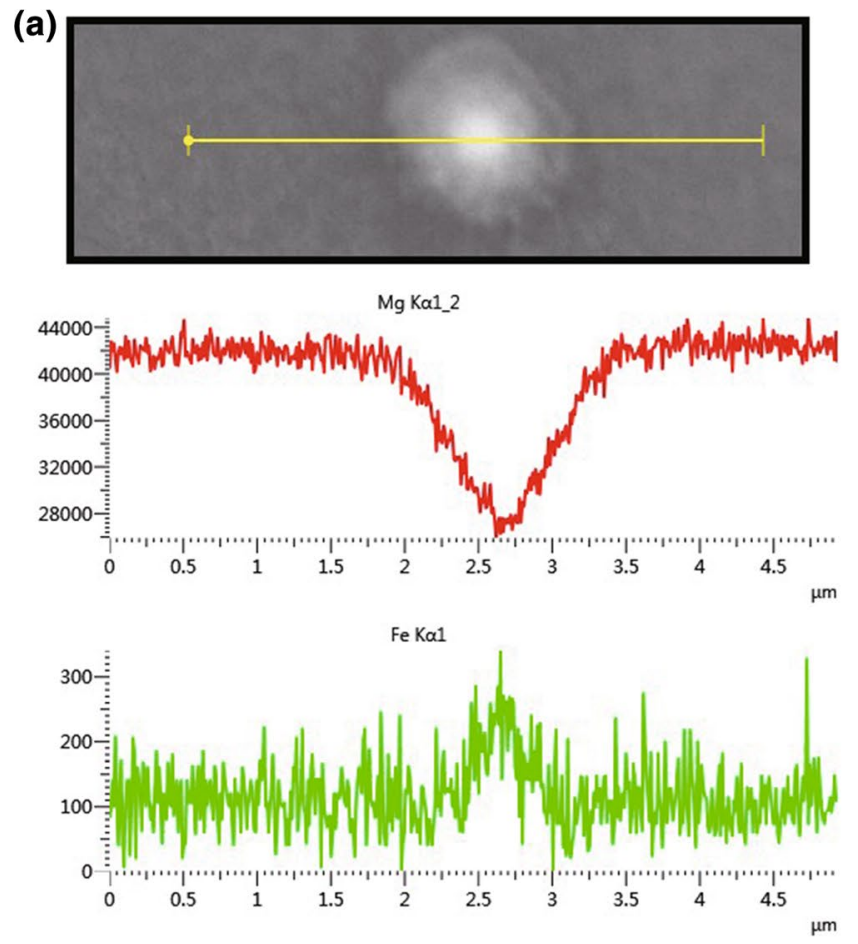

\subsection{Corrosion Rate and Surface Morphology}

The corrosion rate can be used to evaluate the corrosion susceptibility of magnesium scrap. The corrosion rate of $1 \#$ alloy $(0.0236 \% \mathrm{Fe})$ is as high as $144.88 \pm 5.22 \mathrm{mg} / \mathrm{cm}^{2}$ day, while with $0.1 \% \mathrm{Mn}$ addition as $2 \#$ alloy, it decreases sharply to $70.09 \pm 3.60 \mathrm{mg} / \mathrm{cm}^{2}$ day. When the Mn content continues to increase as $3 \#$ alloy $(0.3 \% \mathrm{Mn}, 0.0201 \% \mathrm{Fe})$, the corrosion rate decreases further to $13.79 \pm 1.17 \mathrm{mg} / \mathrm{cm}^{2}$ day. However, as 4\#, 5\#, 6\# alloys, when the Fe content is less than $0.0182 \%$, and the Mn content is more than $0.5 \%$, their corrosion rate remains at a low level, just about $0.38 \pm 0.09$ to $0.54 \pm 0.15\left(\mathrm{mg} / \mathrm{cm}^{2}\right.$ day). It was well known that even a small amount of iron impurities can reduce the corrosion resistance of magnesium alloys. However, reasonable control of Mn addition can weaken the adverse effects of iron impurity and reduce the corrosion susceptibility of magnesium scrap, which will also be discussed later.

Figure 3 shows the typical morphology of the surfaces of the alloy samples after immersion in $3.5 \mathrm{wt} \% \mathrm{NaCl}$ solution

(b)
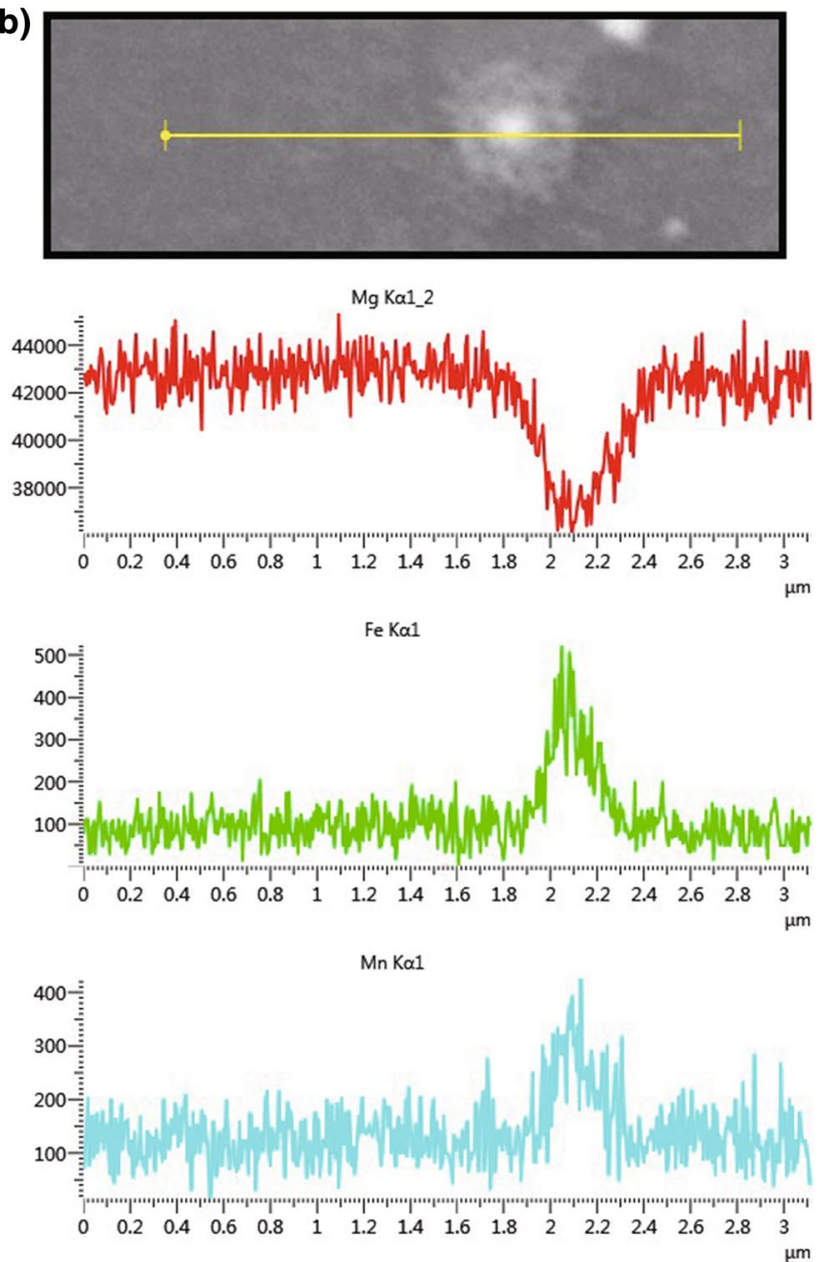

Fig. 2 EDS element line scanning spectrums of Fe-rich particles: a 1\# alloy; b 4\# alloy 

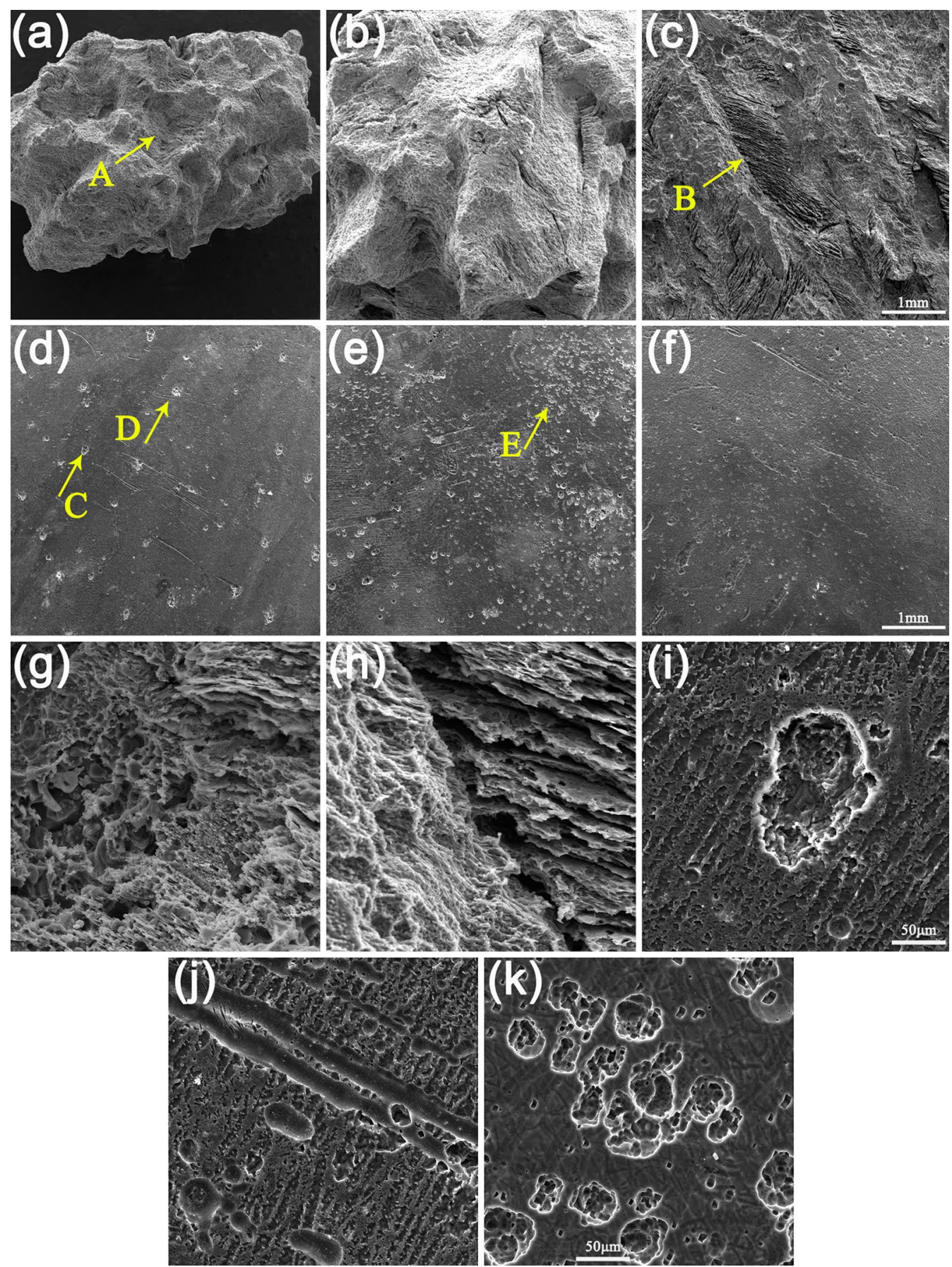

Fig. 3 Scanning electron micrographs showing typical corrosion morphology of the $\mathrm{Mg}-\mathrm{Mn}-\mathrm{Fe}$ alloy samples after immersion in $3.5 \mathrm{wt} \% \mathrm{NaCl}$ solution for $48 \mathrm{~h}$ with the corrosion products removing: a $1 \#, \mathbf{b} 2 \#, \mathbf{c} 3 \#$, d $4 \#$, e $5 \#, \mathbf{f} 6 \#$, $\mathbf{g}$ high magnification of the marked area A in a, h high magnification of the marked area B in $\mathbf{c}, \mathbf{i} \mathbf{j}$ high magnification of the marked area $\mathrm{C}$ and $\mathrm{D}$ in $\mathbf{d}, \mathbf{k}$ high magnification of the marked area $\mathrm{E}$ in $\mathbf{e}$

for two days and removal of corrosion products. Severe corrosion was observed on the surface of 1\#, 2\# and 3\# alloy specimens for the significant reduction in volume, as shown in Fig. 3a-c. The severe localized corrosion sites formed on the surface of these alloys have the same morphological features, exhibiting a honeycomb-like structure composed of crisscrossed and interconnected holes. Besides, some striated features proceeding along specific directions are naturally found, as indicated by the yellow arrow in Fig. 3a, c. At high magnification, the striated regions show a layered structure (see Fig. 3g, h), which is formed due to different dissolution rates of crystal plane with different orientations 
$[13,14,21,22]$. Slight corrosion was observed on the surface of 4\#, 5\#, 6\# alloy specimens, as shown in Fig. 3d-f. As for $4 \#$ alloy specimen, pitting corrosion with the average diameter of $99.83 \mu \mathrm{m}$ (see Fig. 3d, i) was observed, and the slight filiform corrosion was randomly distributed on the surface (see Fig. 3d, j). The corrosion of magnesium alloys typically takes the form of micro-galvanic corrosion, which could germinate along the second phase of the alloy due to the potential difference between the second phase (Fe impurity) and the magnesium matrix. The filiform corrosion morphology is caused by an active corrosion cell that moves across a metal surface [23]. As for $5 \#$ and $6 \#$ alloys, the average diameter of corrosion pits decreases to 64.89 and $48.28 \mu \mathrm{m}$, which is attributed to a reduction in galvanic potential difference between the $\alpha-\mathrm{Mg}$ phase and $\mathrm{Fe}-\mathrm{Mn}$ particle with symbiotic structure [20, 24]. However, the increase of galvanic couple consisting of $\mathrm{Mn}$ phase and $\alpha-\mathrm{Mg}$ phase could promote the initiation of pitting corrosion, causing a significant increase in the number of corrosion pits, as shown in Fig. 3e, f.

\subsection{Macro-Corrosion Process}

Figure 4 shows the macroscopic corrosion morphology evolution of the alloy samples in $3.5 \mathrm{wt} \% \mathrm{NaCl}$ solution with different immersion times. When the specimen was immersed in the solution, many small hydrogen bubbles were immediately formed on the surface of $\mathrm{Mg}$. After soaking for a period of time $(0.3 \mathrm{~h})$, the hydrogen stream bubbles were generated at some points of the surface of $1 \#$ and 2\# alloy samples, while the bubbles on the surface of other alloys (3\#, 4\#, 5\# and 6\# alloys) were relatively weak, as shown with the red arrow in Fig. 4. That means that the corrosion rate of $1 \#$ and $2 \#$ alloys is faster than that of $3 \#$, $4 \#, 5 \#$ and $6 \#$ alloys. In general, the localized corrosion occurred at the sites with corroded dark surface, and the hydrogen stream appeared. As for the 1\#, 2\# and 3\# alloys, with the further extension of immersion time as $4.0 \mathrm{~h}$, these localized corrosion sites developed gradually, with dark corrosion products and a strong hydrogen stream on the surface. In addition, the formation of corrosion products underneath the $\mathrm{Mg}(\mathrm{OH})_{2} / \mathrm{MgO}$ film catalyzes the corrosion process of $\mathrm{Mg}$ alloys [25], making the contribution of reactions in dark areas to the global hydrogen evolution rate stronger. When immersion time is longer than $12 \mathrm{~h}$, the dark corrosion zone extended to the whole surface of the alloy and to the depth at the same time. After immersion for about $24 \mathrm{~h}$, the rough and thin corrosion products fell off obviously to the periphery, with its color becoming light. However, as for 4\#, 5\# and 6\# alloys, when the immersion time varied from 4 to $24 \mathrm{~h}$, the silvery surface changed little but only with a few localized corrosion sites (see Fig. 4), indicating that a more protective surface film was formed on the surface of these alloys.

Figure 5 shows the SEM of corrosion morphology and EDS results of 1\# and 4\# alloy samples after immersion in

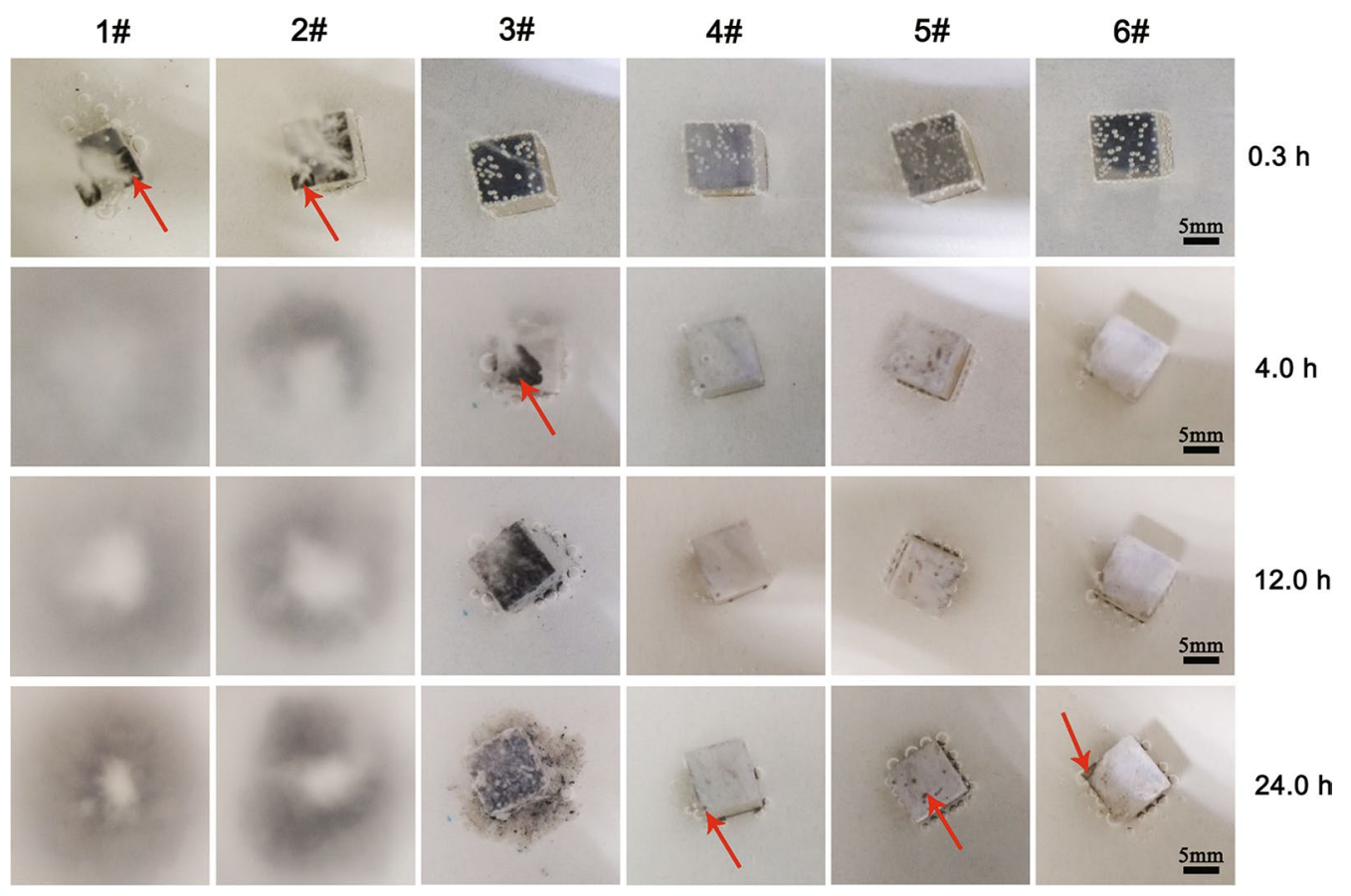

Fig. 4 Optical images showing the macro-corrosion morphology evolution on the surfaces of the $\mathrm{Mg}-\mathrm{Mn}-\mathrm{Fe}$ alloy samples during immersion in $3.5 \mathrm{wt} \% \mathrm{NaCl}$ solution 

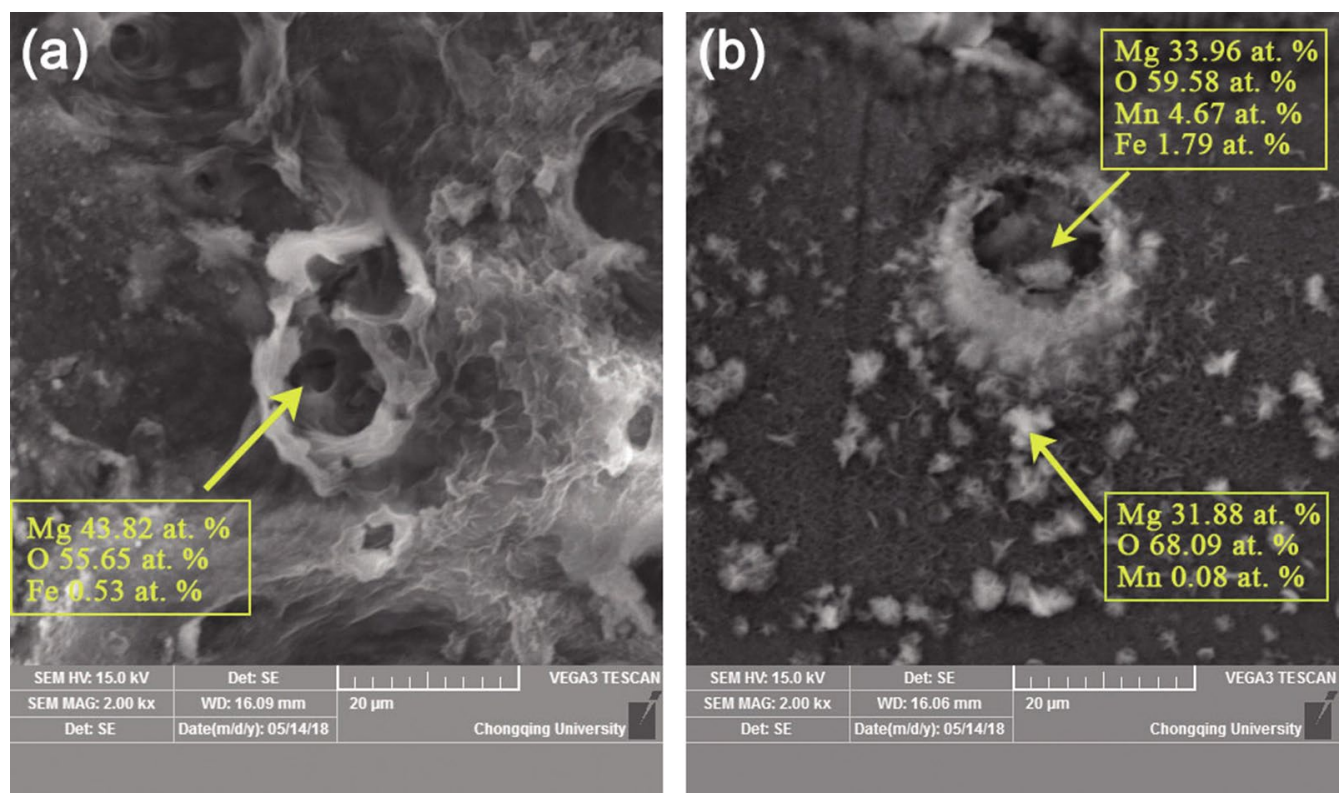

Fig. 5 SEM of corrosion morphologies and EDS results of alloy samples in $3.5 \mathrm{wt} \% \mathrm{NaCl}$ solution for $1 \mathrm{~h}$ : a $1 \#$ alloy; b $4 \#$ alloy

$3.5 \mathrm{wt} \% \mathrm{NaCl}$ solution for $1 \mathrm{~h}$. It can be seen that the localized corrosion morphology of $1 \#$ alloy was severe as the corrosion products fell off seriously, with the diameter of localized corrosion holes being larger, as indicated by the white arrow in Fig. 5a. The Fe-rich particles, mainly composed of $\mathrm{Fe}, \mathrm{O}$, and $\mathrm{Mg}$ elements, can be found at the bottom of the localized corrosion hole. Compared with the corrosion morphology of 1\# alloy, the localized corrosion of 4\# alloy was relatively mild, and the diameter of localized corrosion holes was smaller, as shown in Fig. 5b. Similarly, the Ferich particles are mainly composed of $\mathrm{Mg}, \mathrm{Mn}, \mathrm{Fe}$, and $\mathrm{O}$ elements. The hydrogen evolution reaction mainly occurs at these Fe-rich sites (active cathode), which is because of the more significant standard electrode potential difference between $\mathrm{Mg}$ and $\mathrm{Fe}$ (more than $1 \mathrm{~V}$ ). Therefore, in some cases, only localized corrosion holes can be found because of the detachment of Fe-rich particles.

\subsection{Electrochemical Behavior}

DC potentiodynamic polarization measurements of the specimens with different levels of $\mathrm{Mn}$ and Fe content were performed scanning from OCP to $400 \mathrm{mV}$ and $-400 \mathrm{mV}$ for characterizing the current response from alloy substrate in $3.5 \mathrm{wt} \% \mathrm{NaCl}$ solution at room temperature. The polarization curves are shown in Fig. 6a, and cathodic Tafel extrapolation
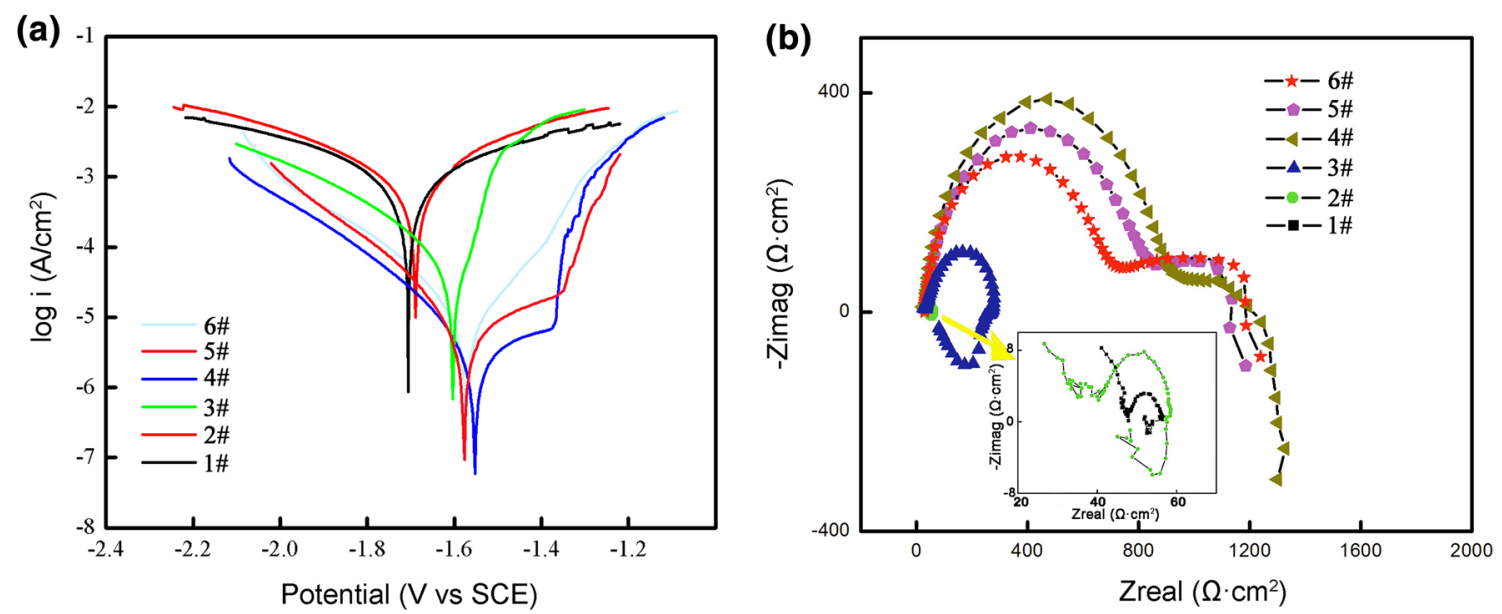

Fig. 6 a Potentiodynamic polarization curves, b EIS spectra of alloys in $3.5 \mathrm{wt} \% \mathrm{NaCl}$ solution 
is applied for analyzing the experimental polarization curves. The cathode reaction in the polarization curves corresponds to the evolution of the hydrogen, while the anodic polarization curve shows important features related to the corrosion resistance [26]. The corrosion potential $E_{\text {corr }}$ of 1\# alloy $(0.0236 \mathrm{wt} \% \mathrm{Fe})$ is $-1707 \mathrm{mV}$, which reveals a positive shift of corrosion potential $E_{\text {corr }}$ to $-1686,-1605,-1550$,$1584,-1572 \mathrm{mV}$ for $2 \#(0.1 \% \mathrm{Mn}, 0.0232 \% \mathrm{Fe}), 3 \#(0.3 \%$ $\mathrm{Mn}, 0.0201 \% \mathrm{Fe}), 4 \#(0.5 \% \mathrm{Mn}, 0.0182 \% \mathrm{Fe}), 5 \#(1.0 \% \mathrm{Mn}$, $0.0172 \% \mathrm{Fe}), 6 \#(2.0 \% \mathrm{Mn}, 0.0079 \% \mathrm{Fe})$ alloys, respectively. It indicates the collective effect of $\mathrm{Mn}$ and $\mathrm{Fe}$ on the respective corrosion reactions in anodic and cathodic domains. The fitted $i_{\text {corr }}$ of the 1\# and 2\# alloys is kept the same order of magnitude as $5.3 \times 10^{-4}$ and $5.2 \times 10^{-4} \mathrm{~A} / \mathrm{cm}^{2}$, while the $i_{\text {corr }}$ of $3 \#$ alloy is more than one order of magnitude higher than that of 1\# and 2\# alloy. It should be noted that no obvious passivation transition region can be distinguished in the anodic zones of these alloys, indicating that the coordination of $\mathrm{Mn}$ and $\mathrm{Fe}$ content does not completely change the weak corrosion resistance of hydro(oxide). In other words, this cooperation of $\mathrm{Fe}$ and $\mathrm{Mn}$ cannot effectively reduce the toxic effects of $\mathrm{Fe}$ impurities, with the corrosion resistance being poor. To be specific, the $i_{\text {corr }}$ of $4 \#, 5 \#$, and $6 \#$ alloys ranges from 3 to $9 \times 10^{-4} \mathrm{~A} / \mathrm{cm}^{2}$ and is about two orders of magnitude lower than that of 1\# and 2\# alloys, which means that these alloys have better corrosion resistance. Also, for the alloy with Mn content more than $0.5 \%$ and Fe content less than $180 \mathrm{ppm}$, the passivation transition region can be easy to find from the anodic branch, indicating the enhancement of barrier properties of the formed corrosion products by the pure $\mathrm{Mg}$. During the refining process, with the Mn addition, the solubility of $\mathrm{Fe}$ in the $\mathrm{Mg}$ matrix decreases, and a higher density of Fe-Mn compound forms and then settles to the melting sludge. Both of them contribute to the formation of a more protective surface film, which ultimately increases the polarization resistance in the corrosive electrolyte.

Electrochemical impedance spectroscopy (EIS) was conducted after the stabilization of the OCP immersion in 3.5 $\mathrm{wt} \% \mathrm{NaCl}$ solution at room temperature, and the EIS spectra (Nyquist plots) are given in Fig. 6b. From a general view of the Nyquist plots, the enhancement of the corrosion resistance of the 4\#-6\# alloys is relatively apparent, as indicated by the larger semicircles in comparison with the 1 \# alloy. It is easy to find that the corrosion resistance of $1 \#, 2 \#$ and $3 \#$ alloys is almost equivalent and minor (approx. $300 \Omega \mathrm{cm}^{2}$ ), which can be explained by the lower standard electrode potential of $\mathrm{Mg}(-2.37 \mathrm{~V})$ and the insufficient protection of the corrosion products as hydro(oxide) layers. Moreover, the existence of a large amount of Fe impurities included the dissolved iron content (iron solubility) and undissolved iron content could aggravate the effect of the micro-galvanic corrosion. However, with the further increase in Mn content and decrease in Fe content, the increase in the diameters of the large semicircles circle may be caused by the increase in compactness/thickness of the hydroxide layer on the $\mathrm{Mg}$ surface blocking the micro-galvanic corrosion between Fe impurities and $\mathrm{Mg}$ substrate [4]. In addition, it is clear that all the Nyquist plots include an inductive loop, indicating that the $\mathrm{Mg}$ electrode is experiencing localized corrosion [27]. All the obtained results of electrochemical measurement agree well with the immersion test and the following surface observation.

\section{Discussion}

\subsection{Corrosion Susceptibility}

According to $\mathrm{Mg}-\mathrm{Fe}$ phase diagram [28], the solubility of $\mathrm{Fe}$ decreases with the decrease in temperature, so the lowtemperature treatment $\left(650^{\circ} \mathrm{C}\right.$ with intentional fluctuation of $\pm 15^{\circ} \mathrm{C}$ ) can accelerate the precipitation of Fe-rich particles from supersaturated solid solution. Moreover, according to the $\mathrm{Mg}-\mathrm{Mn}-\mathrm{Fe}$ phase diagram [29], the addition of $\mathrm{Mn}$ can also decrease the solubility of $\mathrm{Fe}$ in the melt. However, the low-temperature treatment $(90 \mathrm{~min})$ can promote the formation and growth of the Fe-rich particles [30,31], including the $\mathrm{Fe}-\mathrm{Mn}$ particles which has a symbiotic structure due to good affinity of Mn and Fe elements [20, 32, 33].

As for 1\# alloy, the Fe-rich particles can form a robust micro-galvanic couple with the Mg matrix. The Fe-rich particles and the Mg matrix together create a mixed potential, which leads to the anodizing and dissolving of $\mathrm{Mg}$ matrix and to the cathodic polarization of the particles of pure insoluble elements such as $\mathrm{Fe}$ and $\mathrm{Mn}$. The difference in corrosion resistance between the 4\#-6\# alloy and the 1\#-3\# alloy is quite obvious, as shown in Figs. 3, 4 and 6. That means that iron has a particularly harmful effect on magnesium alloy when the iron content exceeds its specific tolerable limit. The total iron content in the alloy includes the dissolved iron content (iron solubility) and undissolved iron content (the free iron). But it is not clear which part of the iron plays an important role in corrosion. According to Reichek et al. [9], the Fe/Mn weigh ratio of the alloy must be within the value of 0.032 (so called critical factor) to ensure that the alloy has better corrosion resistance. In other words, the corrosion rate of magnesium alloy could be controlled with a low value when the $\mathrm{Fe} / \mathrm{Mn}$ ratio is lower than the critical factor.

Figure 7 and Table 2 show the iron content and corrosion performance of the alloy samples. The black curve (a) in Fig. 7 represents the iron solubility as a function of Mn content in the $\mathrm{Mg}-\mathrm{Mn}-\mathrm{Fe}$ system at $650{ }^{\circ} \mathrm{C}$. Due to the addition of $\mathrm{Mg}-\mathrm{Mn}$ master alloys with a certain $\mathrm{Fe}$ impurities, the total iron content in the melt maintains a downward trend, as shown in the blue curve (c). As for the alloy without $\mathrm{Mn}$ 


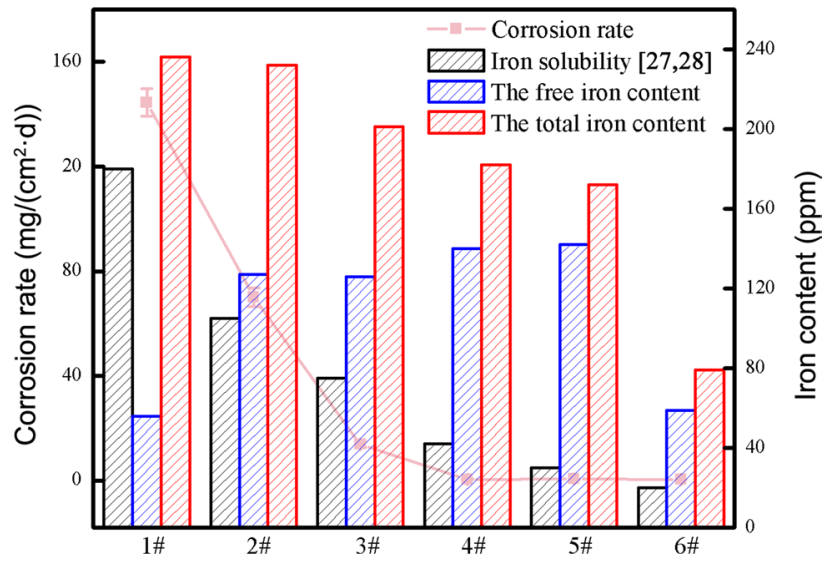

Fig. 7 Changes in iron solubility, the free iron, the total iron and corrosion performance of the $\mathrm{Mg}-\mathrm{Mn}-\mathrm{Fe}$ alloy samples

addition (1\# alloy), despite the fact that the free Fe content (56 ppm) is low, the solubility of $\mathrm{Fe}$ in the $\mathrm{Mg}$ matrix is high (about $180 \mathrm{ppm}$ ), resulting in a high corrosion rate as $144.8 \pm 5.22 \mathrm{mg} / \mathrm{cm}^{2}$ day. With the increase in Mn content from 0 to $0.1 \%$, the solubility of Fe decreases sharply from 180 to $105 \mathrm{ppm}$, while the content of free $\mathrm{Fe}$ increases from 56 to $127 \mathrm{ppm}$. However, the corrosion rate decreases to $70.09 \pm 3.60 \mathrm{mg} / \mathrm{cm}^{2}$ day, indicating that the addition of
Mn significantly reduces the galvanic corrosion between the Fe particles and the $\mathrm{Mg}$ matrix. When the Mn content increases to $0.3 \%$, the free Fe content is almost unchanged, but the solubility of Fe decreases. The final corrosion rate decreases significantly as $13.79 \pm 1.17 \mathrm{mg} / \mathrm{cm}^{2}$ day, indicating that the solubility of $\mathrm{Fe}$ is the main factor affecting the corrosion rate. Although the free Fe content of 4\# and 5\# alloys remains at a higher level as about $140 \mathrm{ppm}$, their corrosion rates are just $0.40 \pm 0.12 \mathrm{mg} / \mathrm{cm}^{2}$ day (4\# alloy) and $0.54 \pm 0.15 \mathrm{mg} / \mathrm{cm}^{2}$ day (5\# alloy), due to their low solubility of $\mathrm{Fe}$ (only about $40 \mathrm{ppm}$ ). As for 1\# and 6\# alloys, the free $\mathrm{Fe}$ content of them is close to each other, but the iron solubility of $6 \#$ alloy is lower than that of $1 \#$ alloy. So, the corrosion rate of $6 \#$ alloy is much lower than that of $1 \#$ alloy. It fully reflects the decisive role of the solubility of $\mathrm{Fe}$ on the corrosion rate. In summary, the corrosion rate of the alloy mainly depends on the solubility of $\mathrm{Fe}$, and the presence of more free $\mathrm{Fe}$ (Fe-rich particles with $\mathrm{Mn}$ ) does not necessarily lead to severe corrosion of the alloy. As more $\mathrm{Fe}$ atoms dissolve in the $\mathrm{Mg}$ matrix, the stability of the film can be decreased and the corresponding mechanism will be reported in future research.

Figure 8 further illustrates the effect of Fe solubility and the total $\mathrm{Fe}$ content on the corrosion rate. It can be seen from Fig. 8a that when the iron solubility is less than $40 \mathrm{ppm}$, the
Table 2 Iron content and corrosion performance of the alloy samples

\begin{tabular}{llllcr}
\hline Alloy & Mn (wt\% $)$ & $\begin{array}{l}\text { The total iron } \\
(\mathrm{ppm})\end{array}$ & $\begin{array}{l}\text { Iron solubility } \\
(\mathrm{ppm})\end{array}$ & $\begin{array}{l}\text { The free iron } \\
(\mathrm{ppm})\end{array}$ & $\begin{array}{r}\text { Corrosion rate } \\
\left(\mathrm{mg} / \mathrm{cm}^{2} \text { day }\right)\end{array}$ \\
\hline $1 \#$ & 0 & 236 & 180 & 56 & $144.88 \pm 5.22$ \\
$2 \#$ & 0.109 & 232 & 105 & 127 & $70.09 \pm 3.60$ \\
$3 \#$ & 0.278 & 201 & 75 & 126 & $13.79 \pm 1.17$ \\
$4 \#$ & 0.503 & 182 & 42 & 140 & $0.40 \pm 0.12$ \\
$5 \#$ & 0.761 & 172 & 30 & 142 & $0.54 \pm 0.15$ \\
$6 \#$ & 1.489 & 79 & 20 & 59 & $0.38 \pm 0.09$ \\
\hline
\end{tabular}
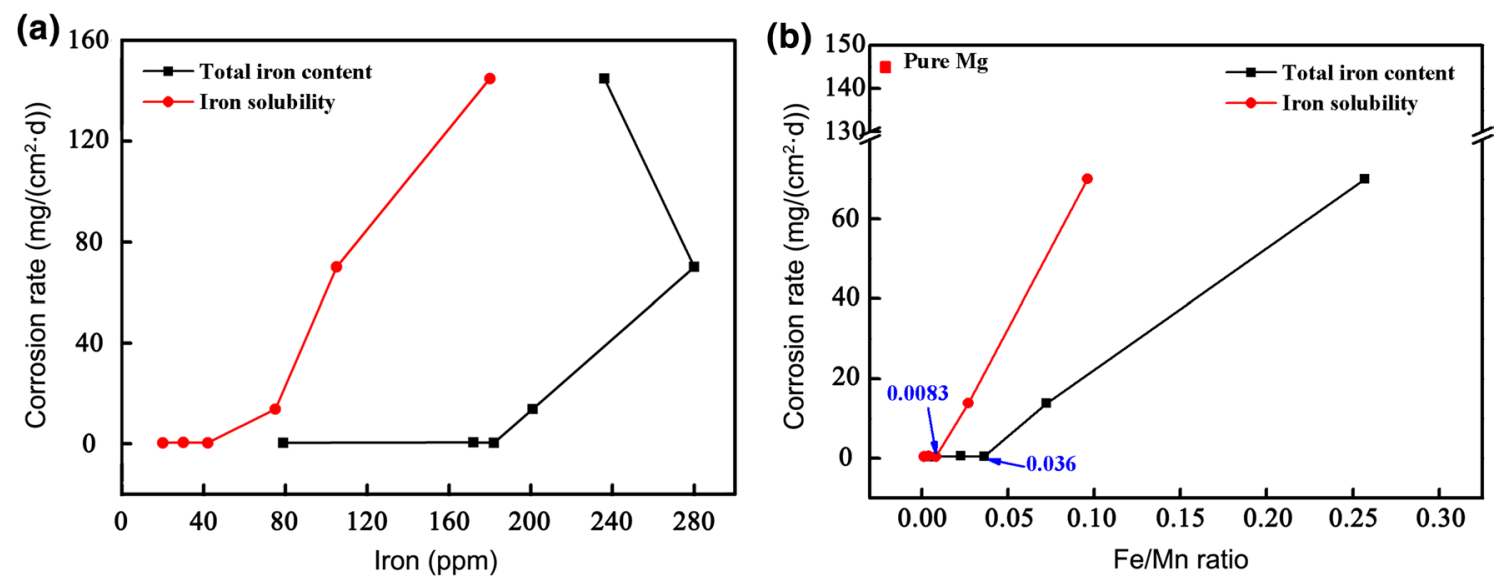

Fig. 8 Corrosion performance vs. the iron content and $\mathrm{Fe} / \mathrm{Mn}$ ratio of $\mathrm{Mg}-\mathrm{Mn}-\mathrm{Fe}$ alloy samples 
alloy maintains excellent corrosion resistance. As we know, the critical factor concerning the $\mathrm{Fe}$ impurity is the $\mathrm{Fe} / \mathrm{Mn}$ ratio rather than the absolute level of Fe concentration. Figure $8 \mathrm{~b}$ shows the relationship between the $\mathrm{Fe} / \mathrm{Mn}$ ratio and the corrosion rate. As indicated in Fig. 8b, the corrosion rate of the cast from the region below the tolerance limit is just about $0.38 \pm 0.09$ to $0.54 \pm 0.15\left(\mathrm{mg} / \mathrm{cm}^{2}\right.$ day), while the corrosion rate of the cast from the region above the tolerance limit increases gradually. Based on the above analysis, the tolerance limit of $\mathrm{Fe}$ impurities can be expressed as $\mathrm{Fe}_{\max }=0.0083 \mathrm{Mn}$ (relative to the iron solubility). Moreover, when the critical $\mathrm{Fe} / \mathrm{Mn}$ ratio is superimposed on the plot of mutual solubility limits, the results (see Fig. 9) can provide convenient guidance for the production of $\mathrm{Mg}-\mathrm{Mn}$ alloys. Since the solubility of $\mathrm{Fe}$ is mainly affected by the refining temperature and the Mn addition, it is possible to indirectly decrease the detrimental effect of Fe impurities by controlling the Mn content with a specific melt refining temperature. Tolerance limits may also be related to the boundary

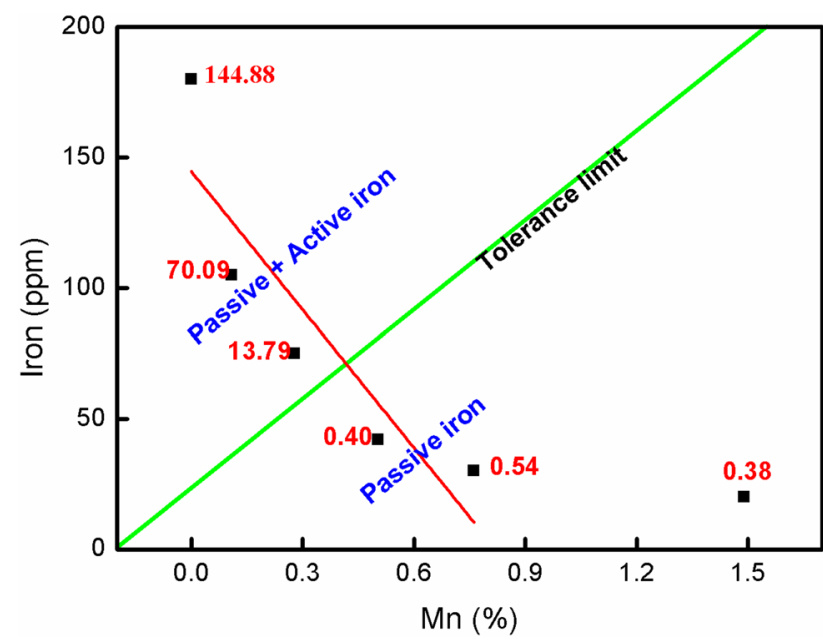

Fig. 9 Fe-Mn solubility limits and the iron tolerance limit. The red numbers adjacent to the data points are the corrosion rates of the $\mathrm{Mg}-$ $\mathrm{Mn}-\mathrm{Fe}$ alloy samples

(a)

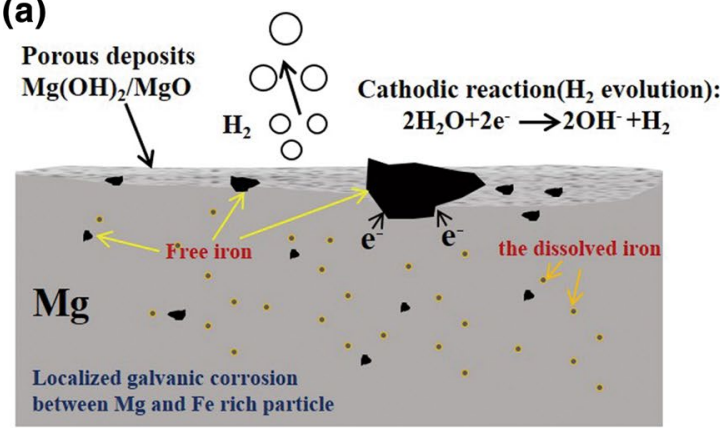

between active and passive forms of iron precipitates. Only when the compositions are below the tolerance limits, both the $\mathrm{Fe}$ and $\mathrm{Mn}$ contents can decrease at the same time.

\subsection{Corrosion Mechanism}

According to the literature [34], the standard reduction potential of $\mathrm{Fe}$ is by far more positive than that of $\mathrm{Mg}(\mathrm{Fe}$ : $-0.78 V_{\text {nhe }} ; \mathrm{Mg}:-2.37 V_{\text {nhe }}$ ), which significantly promotes the occurrence of galvanic corrosion. In general, due to the low solubility of $\mathrm{Fe}$ in the $\mathrm{Mg}$ matrix, the Fe-rich particles tend to precipitate during the melt solidification process, which can be distinguished by SEM and EDS in this study (see Fig. 1). The schematic illustration of pure Mg during the corrosion process is shown in Fig. 10a. During the dissolution of anodic magnesium, hydrogen evolution reaction [35] mainly occurs at these Fe-rich sites (active cathode). The anodic oxidation kinetics is primarily supported by the cathodic reaction of Fe-rich particles. As the surface area of $\mathrm{Fe}$-rich particles increases and the cathode reaction kinetics increases during $\mathrm{Mg}$ dissolution (see Figs. 3, 4), the Ferich particles are usually located at the center of the corrosion sites and buried under the layer of the film (see Fig. 5). Exposure of 1\# alloy (pure $\mathrm{Mg}$ ) in $3.5 \mathrm{wt} \% \mathrm{NaCl}$ solution leads to rapid corrosion with extensive, thick and porous $\mathrm{Mg}(\mathrm{OH})_{2}$ formation covering the thin $\mathrm{MgO}$ film, which are attributed to the relatively high solubility of Fe in the $\mathrm{Mg}$ matrix $[36,37]$. This highly porous nature of the $\mathrm{Mg}(\mathrm{OH})_{2}$ film formed in the solution does not protect the alloy at all, as it does not inhibit the solution from infiltrating into the inner regions of the film and the film-metal interface.

However, as for the alloy with a Fe/Mn ratio higher than 0.0083 , the corrosion resistance is inadequate because the coordination of $\mathrm{Mn}$ and $\mathrm{Fe}$ contents does not entirely change the weak corrosion resistance of hydro(oxide). Only when the $\mathrm{Fe} / \mathrm{Mn}$ ratio is in a specific relationship, the alloy has excellent corrosion resistance (see Fig. 6). During the corrosion of $\mathrm{Mg}, \mathrm{Fe}$ impurity may dissolve into the solution and get reduced to a simple substance by magnesium. Finally,

(b)

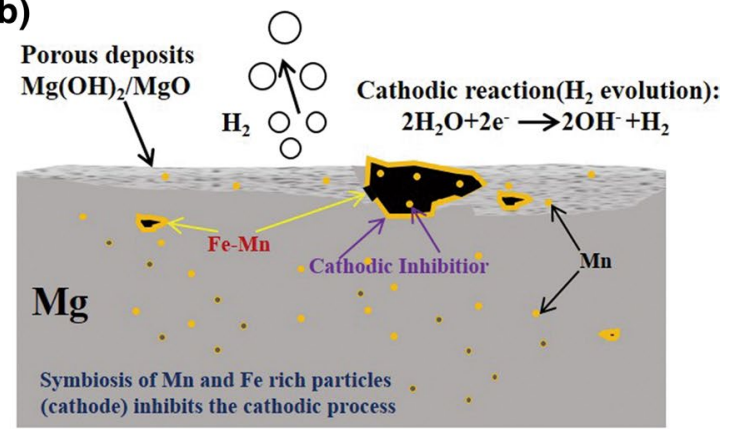

Fig. 10 Schematic illustrations of a $\mathrm{Mg}-\mathrm{Fe}, \mathbf{b} \mathrm{Mg}-\mathrm{Mn}-\mathrm{Fe}$ alloy during the corrosion process 
the Fe element re-deposits on the surface of magnesium and then promotes the occurrence of micro-galvanic corrosion [38]. Experimental evidence shows that the increase in the cathodic area is related to the re-deposition of dissolved iron species at the Mg surface. Therefore, with the decrease in $\mathrm{Fe}$ solubility, the adverse effects of the dissolved $\mathrm{Fe}$ will be significantly reduced. Mn itself cannot improve the corrosion resistance of magnesium, but it can effectively reduce the harmful effect of Fe impurity, probably by the following mechanism. On the one hand, Mn addition can not only reduce the solubility of $\mathrm{Fe}$ in the melt, but also form a higher density of Fe-Mn compound, which then settles to the bottom of the melt and purifies the melt. On the other hand, the $\mathrm{Fe}-\mathrm{Mn}$ particles with a symbiotic structure can act as a barrier for the electrochemical potential difference between $\mathrm{Mg}$ and $\mathrm{Fe}$, reducing the deleterious effect of Fe impurities on the alloy, as shown in Fig. 10b. In other words, this lower influence of micro-galvanic corrosion is attributed to an increased resistance between the $\alpha-\mathrm{Mg}$ phase and $\mathrm{Fe}-\mathrm{Mn}$ particles, thereby improving the corrosion resistance of $\mathrm{Mg}-\mathrm{Mn}-\mathrm{Fe}$ alloy.

\section{Conclusion}

In this study, the microstructure of Fe-rich particle and anticorrosion behavior of magnesium scrap by Mn modification have been investigated. The results show that the corrosion resistance of magnesium scrap can be further controlled by the Mn addition. The Mn-containing Fe-rich particles with unique symbiotic structure can effectively reduce the toxic effects of Fe impurities, and the presence of more free $\mathrm{Fe}$ (Fe-rich particles) does not necessarily lead to severe corrosion of the alloy. The corrosion susceptibility of $\mathrm{Mg}-\mathrm{Mn}-\mathrm{Fe}$ alloy mainly depends on Fe solubility, which can be significantly reduced by suitable Mn addition. Only when Fe/Mn ratio is below 0.0083 (relative to the iron solubility) can the alloy have better corrosion resistance, with a corrosion rate of $0.38 \pm 0.09$ to $0.54 \pm 0.15 \mathrm{mg} / \mathrm{cm}^{2}$ day and an $i_{\text {corr }}$ of 3 to $9 \times 10^{-4} \mathrm{~A} / \mathrm{cm}^{2}$.

Acknowledgements This work was financially supported by the National Key Research and Development Program of China (No. 2016YFB0301100), the Fundamental Research Funds for the Central Universities (No. 2018CDJDCD0001) and the Key Nature Science Foundation of Chongqing (No cstc2017jcyjBX0040).

\section{References}

[1] T. Tu, X.H. Chen, J. Chen, C.Y. Zhao, F.S. Pan, Acta Metall. Sin. Engl. Lett. 32, 23 (2019)

[2] M. Nabiyouni, T. Brückner, H. Zhou, U. Gbureck, S.B. Bhaduri, Acta Biomater. 66, 23 (2018)
[3] N. Sezer, Z. Evis, S.M. Kayhan, A. Tahmasebifar, M. Koç, J. Magnes. Alloy. 6, 23 (2018)

[4] L.X. Wang, R.B. Song, C.H. Cai, J.Y. Li, Acta Metall. Sin. Engl. Lett. 32, 10 (2019)

[5] G.S. Frankel, A. Samaniego, N. Birbilis, Corros. Sci. 70, 104 (2013)

[6] Z.M. Shi, J.X. Jia, A. Atrens, Corros. Sci. 60, 296 (2012)

[7] S. Simanjuntak, M.K. Cavanaugh, D.S. Gandel, M.A. Easton, M.A. Gibson, N. Birbilis, Corrosion 71, 199 (2015)

[8] J.Y. Lee, G. Han, Y.C. Kim, J.Y. Byun, J.I. Jang, H.K. Seok, S.J. Yang, Met. Mater. Int. 15, 955 (2009)

[9] K. Riechek, K. Clark, J. Hillis, SAE Technical Paper Series 850417 (Inc., Warrendale, Pennsylvania, 1985)

[10] J. Hillis, S. Shook, SAE Technical Paper Series 890205 (Inc., Warrendale, Pennsylvania, 1989)

[11] W. Mercer, J. Hillis, SAE Technical Paper Series 920073 (Inc., Warrendale, Pennsylvania, 1992)

[12] M. Liu, P. Uggowitzer, P. Schmutz, A. Atrens, JOM 60, 39 (2008)

[13] L. Yang, X.R. Zhou, M. Curioni, S. Pawar, H. Liu, Z.Y. Fan, G. Scamans, G. Thompson, J. Electrochem. Soc. 162, C362 (2015)

[14] L. Yang, G.K. Liu, L.G. Ma, E.L. Zhang, X.R. Zhou, G. Thompson, Corros. Sci. 139, 421 (2018)

[15] R. Baboian (ed.), Corrosion Tests and Standards: Application and Interpretation (ASTM International, Pennsylvania, 2005)

[16] B.A. Shaw, R.C. Wolfe (ed.), Corrosion Resistance of Magnesium Alloys (ASM International, Materials Park, OH, 2005)

[17] J.D. Hanawalt, C.E. Nelson, J.A. Peloubet, Trans. AIME 147, 273 (1942)

[18] M. Liu, P.J. Uggowitzer, A.V. Nagasekhar, P. Schmutz, M. Easton, G.L. Song, A. Atrens, Corros. Sci. 51, 602 (2009)

[19] L. Yang, X.R. Zhou, S.M. Liang, R. Schmid-Fetzer, Z.Y. Fan, G. Scamans, J. Robson, G. Thompson, J. Alloys Compd. 619, 396 (2015)

[20] J.G. Kim, S.J. Koo, Corrosion 56, 380 (2000)

[21] G. Han, J.Y. Lee, Y.C. Kim, J.H. Park, D.I. Kim, H.S. Han, S.J. Yang, H.K. Seok, Corros. Sci. 63, 316 (2012)

[22] G.L. Song, R. Mishra, Z.Q. Xu, Electrochem. Commun. 12, 1009 (2010)

[23] G.L. Song, A. Atrens, Adv. Eng. Mater. 1, 11 (1999)

[24] O. Lunder, T.K. Aune, K. Nisancioglu, Corrosion 43, 291 (1987)

[25] W.J. Binns, F. Zargarzadah, V. Dehnavi, J. Chen, J.J. Noel, D.W. Shoesmith, Corrosion 75, 58 (2019)

[26] Z. Rajabalizadeh, D. Seifzadeh, Prot. Met. Phys. Chem. Surf. 50, $516(2014)$

[27] J. Chen, J.Q. Wang, E.H. Han, J.H. Dong, W. Ke, Electrochim. Acta 52, 3299 (2007)

[28] A. Nayeb-Hashemi, J. Clark, L. Swartzendruber, Bull. Alloy Phase Diagr. 6, 235 (1985)

[29] L. Ansara, Mem. Sci. Rev. Metall. 88, 711 (1991)

[30] H. Ohta, H. Suito, ISIJ INT 46, 42 (2006)

[31] L.Z. Wang, S.F. Yang, J.S. Li, S. Zhang, J.T. Ju, Metall. Mater. Trans. B 48, 805 (2017)

[32] J.D. Robson, D.T. Henry, B. Davis, Acta Mater. 57, 2739 (2009)

[33] D.S. Gandel, M.A. Easton, M.A. Gibson, N. Birbilis, Mater. Chem. Phys. 143, 1082 (2014)

[34] G.L. Song, A. Atrens, M. Liu, Z.M. Shi, F.Y. Cao, M.S. Dargusch, Adv. Eng. Mater. 17, 400 (2015)

[35] B.Y. Qian, W. Miao, M. Qiu, F. Gao, D.H. Hu, J.F. Sun, R.Z. Wu, B. Krit, S. Betsofen, Acta Metall. Sin. Engl. Lett. 32, 194 (2019)

[36] L. Kumari, W.Z. Li, C.H. Vannoy, R.M. Leblanc, D.Z. Wang, Ceram. Int. 35, 3355 (2009)

[37] K.A. Yasakau, D. Hoeche, S.L. Lamaka, M.G.S. Ferreira, M.L. Zheludkevich, Corrosion 73, 583 (2017)

[38] S. Thomas, N.V. Medhekar, G.S. Frankel, N. Birbilis, Curr. Opin. Solid. State Mater. Sci. 19, 85 (2015) 